\title{
Oliver Wells: My Recollections
}

\author{
Fabian Pease ${ }^{1}$ \\ ${ }^{1}$ Stanford University, CA 94305, USA
}

When I entered Cambridge University as a freshman in 1957 I made friends with a group of physics students from Bristol University. Their hobby was caving, primarily in the Mendip hills near Bristol and I joined them in this activity. Most of the caving there could be done without diving through sumps; that is, where the passage is completely filled with water. But there was one cave with the ominous name of 'Wookey Hole' that required diving through a series of sumps to get to the further chambers. Wookey had claimed at least one life because, unlike scuba diving in open water, you cannot get to the surface in a hurry if something goes wrong. But they told me about one person who had successfully gone further than anyone into Wookey (and made it out alive) and his name was Oliver Wells who was no longer in the area but no one seemed to know where he had gone.

In the Autumn of 1960 I began my graduate research on the scanning electron microscope (SEM) under the direction of Prof. Charles Oatley. Richard Thornley was just finishing and he had, three years earlier, inherited the SEM that one O.C. Wells had built. Naturally I asked if this was 'the famous Oliver Wells the cave diver' and of course it was. Indeed it turned out that Oliver's activities had been as much into cave diving as into his SEM research.

In 1962 I became aware that Oliver had joined forces with Tom Everhart and Richard Matta at the Westinghouse Research labs. and were building an SEM there to study the applications of the SEM to the nascent semiconductor industry. Tom concentrated on the SEM for looking at semiconductor devices and Oliver would be looking at the SEM as a lithographic tool. This interested me in particular as I was hoping to do the same thing with the SEM that I was building.

Tom's time at Westinghouse was an 'industrial leave' from his regular professorship at U.C. Berkeley and came to an end some time in 1963. He did indeed lay the groundwork for the subsequent vigorous activity world wide in the use of the SEM for examining semiconductor devices. In the Spring of 1964 I had graduated and Alec Broers and I went to the 'Three Beams' meeting (as it was later known) in Toronto where we met Oliver and Tom for the first time. Oliver was still at Westinghouse working on electron beam lithography and that team developed not only a scanning electron beam for pattern generation and also a projection technique 'Electron Image Projection System' which could expose a whole wafer (<2" diameter) in 60 seconds. However the project came to an end in about 1966 (by which time I had joined Tom at Berkeley) and Oliver joined the staff at the IBM Watson Research Center.

It was at Watson that he made probably his most significant invention which was to use only the elastically reflected electrons to build up the image. He and Alec Broers employed this technique on a high resolution SEM that Alec had built and demonstrated a resolution on a bulk sample of about 2.6nm. This was significantly better than any other SEM up to that time.

Since about 1980 I kept in touch with Oliver mostly at the annual SPIE meeting on 'Advanced Lithography. He continued to be active in the SEM both in terms of research and in his taking on the job of writing reviews and a history of the SEM. However the last time I talked with him he had been back 
to the UK and had indeed gone down a cave or two while there and he allowed that he found he no longer could negotiate the boulders and squeezes with his previous facility. But I was impressed that a $70+$ year old man could even venture down those caves. 